\title{
KERJASAMA DIREKTORAT JENDERAL IMIGRASI DENGAN UNHCR (UNITED NATIONS HIGH COMMISSIONER FOR REFUGEES)
}

\author{
David Fernando $^{(1)}$, Razico P Putra ${ }^{(2)}$, Satria Yulanda ${ }^{(3)}$ \\ 1,2,3 Politeknik Imigrasi Badan Pengembangan Sumber Daya Manusia Hukum dan HAM RI. Indonesia \\ e-mail:davidfernando190999@gmail.com,razicopp@gmail.com, satriayulanda1582@gmail.com
}

\begin{abstract}
The United Nations has formed a special international organization that is responsible for handling refugees internationally. The organization is called the United Nations High Commissioner for Refugees (UNHCR). This international organization deals specifically with refugees, asylum seekers, stateless people and internally displaced persons. The tasks of the UNCHR include determining refugee status, relations with government and capacity building, community-based cooperation and protection, comprehensive solutions, and preventing statelessness. UNHCR plays an important role as a determinant of refugee status and as an initiator / facilitator of protection and assistance for refugees. Apart from that in dealing with refugees. UNHCR carries out various strategic collaborations with other regional / international organizations such as UNICEF, UNDP, UNWFP, WHO. UNHCR is a special UN organization that was formed for the purpose of protecting and guaranteeing human rights and efforts to humanize international refugees, as a result of a war or prolonged armed conflict, internal conflicts and various other domestic problems.
\end{abstract}

Keywords :Cooperation, Immigration, Refugees, UNHCR

\begin{abstract}
ABSTRAK
PBB membentuk suatu organisasi internasional khusus yang bertanggungjawab dalam penanganan pengungsi secara internasional. Organisasi tersebut dinamakan United Nations High Commissioner for Refugees (UNHCR). Organisasi internasional ini secara khusus menangani pengungsi, pencari suaka, orang-orang tanpa kewarganegaran, dan pengungsi internal. Tugas dari UNCHR meliputi tentang penentuan status pengungsi, relasi dengan pemerintah dan peningkatan kapasitas, kerjasama dan perlindungan berbasis komunitas, solusi komprehensif, dan mencegah keadaan tanpa kewarganegaraan. UNHCR berperan penting sebagai determinator status pengungsi dan sebagai inisiator/fasilitator perlindungan dan bantuan terhadap para pengungsi. Selain itu dalam menangani pengungsi UNHCR melakukan berbagai kerjasama yang strategis dengan organisasi regional/internasional lainnya seperti UNICEF, UNDP, UNWFP, WHO. UNHCR merupakan organisasi khusus PBB yang dibentuk untuk tujuan melindungi dan menjamin HAM serta upaya memanusiawikan para pengungsi internasional, sebagai akibat dari suatu peperangan ataupun konflik bersenjata yang berkepanjangan, pertikaian internal dan berbagai persoalan dalam negeri lainnya.
\end{abstract}

Kata kunci: Kerjasama, Imigrasi, Pengungsi, UNHCR 


\section{Pendahuluan}

PBB membentuk suatu organisasi internasional khusus yang bertanggungjawab dalam penanganan pengungsi secara internasional. Organisasi tersebut dinamakan United Nations High Commissioner for Refugees (selanjutnya disebut UNHCR). Organisasi internasional ini secara khusus menangani pengungsi, pencari suaka, orangorang tanpa kewarganegaran, dan pengungsi internal. Tugas dari UNCHR meliputi tentang penentuan status pengungsi, relasi dengan pemerintah dan peningkatan kapasitas, kerjasama dan perlindungan berbasis komunitas, solusi komprehensif, dan mencegah keadaan tanpa kewarganegaraan. UNHCR merupakan organisasi khusus PBB yang dibentuk untuk tujuan melindungi dan menjamin HAM serta upaya memanusiawikan para pengungsi internasional, sebagai akibat dari suatu peperangan ataupun konflik bersenjata yang berkepanjangan, pertikaian internal dan berbagai persoalan dalam negeri lainnya.

Disadari bahwa problem migrasi internasional pada masa sekarang ini telah menjadi persoalan setiap negara, baik negara asal, negara tujuan maupun negara transit. Masalah ini juga bukan hanya menjadi masalah negara berkembang tetapi juga urusan negara maju yang umumnya menjadi negara tujuan. Semua ini merupakan rangkaian yang saling berhubungan satu dan yang lain. Banyak negara maju membuat suatu ketentuan ketat dalam menghadapi kaum migran atau pengungsi asing. Parameter yang digunakan salah satunya melalui hukum yang ketat tetapi tetap memperhatikan aspek-aspek hak asasi manusia. Hal tersebut merupakan cara baru dalam mengatur persoalan migrasi internasional.

Pada umumnya negara-negara berpandangan bahwa masalah migrasi internasional dapat diselesaikan secara mandiri. Namun masalah migrasi internasional ini diperlukan kerjasama antar negara atau perlu dikaji dalam hal hubungan internasional yang saling terkoneksi. Migrasi internasional tidak sekedar masalah pencarian kerja di suatu negara, tetapi juga menyangkut status hukum, perlindungan, dan hak asasi manusia.

Berdasarkan pada Konvensi 1951 tentang status pengungsi, mendefinisikan pengungsi yaitu adalah orang yang dikarenakan oleh ketakutan yang beralasan akan penganiayaan, yang disebabkan oleh alasan ras, agama, kebangsaan, keanggotaan dalam kelompok sosial dan partai politik tertentu, berada di luar negara kebangsaannya dan tidak menginginkan perlindungan dari negara tersebut.

Indonesia belum meratifikasi konvensi 1951. Oleh karena itu Indonesia menyerahkan penanganan pengungsi pada UNHCR. Serta melakukan aktifitasnya berdasarkan mandat dari pihak penandatanganan pada konvensi 1951 di negara-negara yang bukan pihak penandatangan. Oleh sebab itu Indonesia tidak memiliki kewenangan untuk menentukan apakah seseorang atau sekelompok orang yang meminta status pengungsi diakui sebagai pengungsi.

Kewenangan tersebut dilakukan oleh UNHCR mengingat Indonesia bukan negara konvensi 1951 dan protokol tahun 1967. Indonesia juga tidak memiliki payung hukum untuk menghadapi pengungsi yang masuk ke Indonesia. Indonesia melakukan tindakan penampungan pada Rudenim yang untuk selanjutnya dilakukan deportasi ke negara asal.

\section{Metode}

\section{Tugas dan Peranan UNHCR Secara Umum}

UNHCR adalah sebuah lembaga yang mempunyai prosedur tetap dalam memberikan bantuan yang berkaitan dengan pemenuhan Hak Asasi Manusia (HAM) berupa perlindungan internasional. Kalau menyinggung penerapan HAM yang efektif maka penerapan HAM harus dilihat secara kontekstual. Asas-asas yang ada dalam HAM 
yang sifatnya universal tapi di sisi lain tidak bisa diterapkan secara sama di dalam konteks yang berbeda-beda. Asas-asas HAM yang sifatnya universal dalam artian bahwa tidak ada satupun negara di dunia ini yang dapat menepuk dada dan mengatakan bahwa ia tidak mempunyai masalah HAM.

UNHCR dibentuk sebagai sebuah manifestasi penegakan HAM di mana mempunyai peranan khusus dalam penegakan HAM yang menyangkut penanganan pengungsi. Secara umum konsep ini berisikan pencegahan bagaimana agar pengungsi ada pemulangan kembali, bantuan dalam proses pencarian suaka, bantuan dan nasihat hukum, pemajuan dan penyelenggaraan keamanan fisik bagi para pengungsi, pemajuan dan pembantuan pemulangan kembali secara sukarela dan membantu para pengungsi untuk bermukim kembali.

Kepercayaan terhadap kredibilitas UNHCR sebagai sebuah lembaga yang menangani pengungsi dengan pemberian mandat untuk pemberian perlindungan terhadap pengungsi internasional merupakan sebuah harapan bahwa kedepannya UNHCR mampu memberikan solusi yang sifatnya permanen terhadap para pengungsi dengan jalan membantu pemerintah-pemerintah, pelaku-pelaku lainnya atau pun organisasiorganisasi kemanusiaan yang terkait untuk memberikan fasilitas pemulangan (repatriation) bagi para pengungsi.

Untuk melaksanakan fungsinya dengan baik sesuai dengan Resolusi Majelis Umum PBB No. 428 (V), diminta kepada negaranegara di dunia untuk bekerja sama dengan UNHCR dalam pelaksanaan fungsifungsinya mengenai para pengungsi yang berada di bawah wewenang kantornya, terutama dengan :

1. Menjadi peserta setiap Konvensi internasional untuk melindungi pengungsi serta melaksanakan aturan dalam Konvensi tersebut;

2. Membuat persetujuan-persetujuan khusus dengan UNHCR untuk pelaksanaan tindakan-tindakan yang diperkirakan akan memperbaiki situasi pengungsi dan untuk mengurangi jumlah pengungsi yang membutuhkan perlindungan;

3. Tidak mengenyampingkan pengungsi yang dalam kategori paling miskin;

4. Membantu UNHCR dalam upaya-upaya untuk mempromosikan repatriasi sukarela;

5. Mempromosikan pembubaran pengungsi terutama dengan memudahkan pewarganegaraan mereka;

6. Memberikan dokumen perjalanan dan dokumen lain pada pengungsi seperti yang biasanya diberikan kepada orangorang asing lain oleh instansi-instansi nasional mereka. Terutama dokumendokumen yang akan memudahkan pemukiman kembali pengungsi;

7. Mengizinkan pengungsi untuk memindahkan aset mereka, terutama aset yang perlu bagi pemukiman mereka;

8. Memberikan informasi kepada UNHCR mengenai jumlah dan kondisi para pengungsi, serta hukum dan peraturanperaturan mengenai mereka.

Pengungsi sebagaimana tersebut di atas segera berhenti jika;

1. Yang bersangkutan secara sukarela telah memanfaatkan Kembali perlindungan yang diberikan oleh negara asalnya; atau

2. Yang bersangkutan telah kehilangan kewarganegaraanya, dan dia secara sukarela telah memperolehnya kembali; atau

3. Dia menikmati perlindungan dari negara barunya itu; atau

4. Dia telah Kembali ke negara asalnya; atau

5. Dia tidak lagi dapat dianggap sebagai pengungsi karena keadaan yang membuatnya diterima sebagai pengungsi telah berakhir. Jadi alasan yang bersifat ekonomi belaka untuk menjadi pengungsi tidak dapat diterima sebagai kompetensi UNHCR; atau 
6. Dia tidak punya kewarganegaraan tetapi keadaan yang membuat dia kehilangan kewarganegaraan telah berakhir.

Selain perlindungan internasional, UNHCR juga diberikan kewenangan untuk:

1. Mempromosikan pembuatan dan peratifikasian konvensi-konvensi internasional tentang perlindungan dan mengawasi aplikasinya serta mengusulkan amandemennya;

2. Mempromosikan melalui perjanjianperjanjian khusus dengan pemerintah setiap ketentuan yang diperkirakan dapat memperbaiki keadaan pengungsi dan mengurangi jumlah pengungsi yang membutuhkan perlindungan;

3. Membantu usaha-usaha pemerintah dan swasta untuk mempromosikan repatriasi sukarela atau pengasimilasian komunitas di negara baru;

4. Mempromosikan penerimaan pengungsi, dengan tidak menyampingkan orangorang yang benar-benar dalam keadaan yang sangat miskin;

5. Mempercepat memperoleh izin bagi pengungsi untuk mentransfer aset mereka terutama untuk kebutuhan pemukiman kembali (resetlement);

6. Memperoleh informasi dari pemerintahpemerintah tentang jumlah dan keadaan pengungsi di wilayah mereka dan hukum serta peraturan-peraturan yang mengatur tentang pengungsi;

7. Menjalin hubungan dengan pemerintahpemerintah dan organisasi-organisasi swasta untuk mengatasi pengungsi;

8. Mengadakan hubungan baik dengan organisasi-organisasi swasta untuk mengatasi pengungsi;

9. Memberikan fasilitas koordinasi terhadap usaha-usaha koordinasi swasta yang terkait dalam meningkatkan kesejateraan pengungsi.

\section{Kerjasama UNHCR dalam mengatasi pengungsi di Indonesia \\ UNHCR berperan untuk mengurus} identitas mereka sebagai pengungsi (refugees) agar mereka tidak di deportasi oleh Pejabat Imigrasi Indonesia. Dan dalam melaksanakan tugasnya, UNHCR sangat terikat pada asas legalitas, yang mana UNHCR hanya dapat melaksanakan tugas berdasarkan ketentuan-ketentuan yang tertulis dalam Statuta, Konvensi, dan Protokol mengenai Status Pengungsi, juga mandat yang di perintahkan oleh Majelis Umum bila terjadi situasi yang mendesak, dan ketentuan-ketentuan perundangundangan dari Pemerintah Indonesia.

Peran UNHCR Indonesia terhadap perlindungan pengungsi Rohingya di Indonesia adalah sebagai organ perwakilan PBB yang berkewajiban untuk memberikan perlindungan kepada para pengungsi, dengan memberikan akses keamanan untuk para pengungsi dengan menjamin mereka masuk ke wilayah yang aman, bahwa mereka dapat menikmati keamanan dari kekerasan dan penganiayaan, bahwa mereka tidak dipaksa kembali (refoulement) ke wilayah di mana kehidupan atau kebebasan mereka akan terancam, bahwa mereka juga diperlakukan sesuai standar hak asasi manusia. UNHCR juga berperan untuk mengadvokasi dan mempromisikan prinsip-prinsip perlindungan internasional dan mandat UNHCR dengan Pemerintah Indonesia melalui pertemuan, pelatihan, dan korespondensi untuk memastikan bahwa Negara Indonesia menerapkan prinsipprinsip ini dalam melindungi orang-orang yang menjadi perhatian UNHCR, yaitu pencari suaka, pengungsi, dan imigran. UNHCR akan selalu memberikan perlakuan yang menjunjung tinggi kemanusiaan untuk melindungi para pengungsi yang dalam keadaanrentan (vulnerable).

Kerjasama Indonesia dan UNHCR telah berlangsung sejak tahun 1979 yaitu lewat Agreement between the Government of the Republic of Indonesia and United Nations High Commissioner for Refugees regarding the Establishment of the Office of the UNHCR Representative for Indonesia yang ditandatangani pada tanggal 15 Juni 1979. 
Pada intinya, perjanjian atau kesepakatan tersebut menyatakan bahwa UNHCR diperbolehkan untuk membuka kantor regional di Indonesia dan turut membantu Indonesia dalam penanganan masalah pengungsi di wilayah Indonesia.

Kerjasama penanganan pengungsi pertamakalinya dilakukan pada saat kedatangan pengungsi dari Vietnam. Dalam rangka untuk penampungan pengungsi tersebut, Indonesia menyediakan Pulau Galang untuk ditempati pengungsi dan mengambil kebijakan untuk mempercepat proses repatriasi atau pemulangan secara sukarela bagi pengungsi Vietnam tersebut ke negara asalnya. UNHCR turut serta bekerjasama dengan Indonesia untuk proses pemulangan tersebut dengan memberikan bantuan dana bagi pengungsi yang berkenaan dengan pemulangan mereka yaitu seperti uang paket dan uang penerbangan. Selain bantuan dana tersebut, tentunya UNHCR juga melaksanakan tugasnya dalam rangka untuk penetapan status pengungsi bagi orangorang yang memenuhi kriteria pengungsi baik menurut instrument internasional maupun instrument regional yang diakui.

Penetapan tersebut dilakukan oleh UNHCR dikarenakan Indonesia bukan merupakan negara pihak Konvensi Jenewa 1951 dan Protokol New York 1967. Bagi negara pihak dari instrument internasional tersebut, tentunya negara pihak dapat melakukan prosedur penentuan status pengungsi secara mandiri. Meskipun begitu, UNHCR juga tetap bekerjasama dengan Indonesia terkait permohonan baru dari status pengungsi. Dari pihak Indonesia akan membawa permohonan baru pengungsi di Indonesia kepihak UNHCR. Kemudian jika status pengungsi disetujui, pihak UNHCR akan memberikan izin tinggal di Indonesia dengan sepersetujuan Pemerintah Indonesia sampai dengan pengungsi tersebut mendapatkan penempatan. Pada tahun 2015, Indonesia dan UNHCR kembali menjalin kerjasama yang dalam hal ini, Indonesia diwakili oleh Komisi Nasional Hak Asasi
Manusia (Komnas HAM) Indonesia. Kedua pihak menandatangani Nota Kesepahaman untuk meningkatkan advokasi dan langkah lainnya yang dirancang untuk perlindungan hak asasi manusia para pengungsi dan pihak lain yang berada di bawah mandat UNHCR di Indonesia. Kemudian kedua belah pihak, baik UNHCR dan Indonesia, membentuk pula suatu jaringan lembaga guna koordinasi mengenai penanganan penyelundupan manusia, pengungsi, dan pencari suaka. Jaringan lembaga tersebut disebut dengan Desk Koordinasi Penanganan Penyelundupan Manusia, Pengungsi, dan Pencari Suaka (P2MP2S).

Kerjasama Drirektorat Jenderal Imigrasi dengan UNHCR antara lain berkontribusi dalam mengatasi permasalahan pengungsi Internasional Di Indonesia. Penanganan pengungsian dapat dilakukan UNHCR melalui: repatriasi sukarela, permukiman lokal, dan pemukiman kembali di negara ketiga. Penangan melalui repratiasi sukarela sangat bergantung pada faktor kondisi di negara asal yang kondusif, sebagaimana UNHCR mengupayakan pemulangan 47 ribu pengungsi Kamboja secara sukarela dari Thailand. Demikian pula pada repatriasi sekitar 1,7 juta pengungsi Mozambique yang kembali antara tahun1993 .Selain itu UNHCR juga mengupayakan bantuan-bantuan bagi proyek pemukiman lokal, baik wilayah pedesaan maupun kota kepada pengungsi. Bagi pengungsi yang tidak dapat kembali ke negara asal atau tidak merasa aman di negara yang menampungnya, satu-satunya solusi adalah dimukimkan di negara ketiga. Pada tahun 1996 sekitar 35.000 pengungsi dari sekitar 40 negara penampung dimukimkan kembali oleh UNHCR keberbagai negara di dunia.

Secara umum, UNHCR sebagai organisasi internasional dan Kemenkumham sebagai perwakilan pemerintah Indonesia memiliki tujuan yang sama yaitu melindungi orang-orang dari luar negeri dari segala ancaman negara asal mereka. Terkait dengan strategi yang dirancang oleh UNHCR 
maupun Kemenkumham yang paling utama adalah dengan memperkuat komunikasi dalam hal pencarian, penemuan hingga pertolongan pengungsi yang datang ke Indonesia. Kedatangan pengungsi bisa terjadi dua kasus yaitu, saat mereka datang, mereka akan melakukan self report dan meminta kepada UNHCR untuk dapat melakukan registrasi. Ada juga kasus ketika mereka datang, mereka ditangkap di pelabuhan atau bandara. Ketika hal seperti itu terjadi, pihak imigrasi akan melakukan Operasi Pencarian dan Pertolongan sesuai dengan yang tertera di Pasal 6 bahwasanya lembaga yang menyelenggarakan urusan di bidang Pencarian dan Pertolongan melaksanakan operasi Pencarian dan Pertolongan terhadap kapal yang diduga berisi Pengungsi yang melakukan panggilan darurat. Selanjutnya pada Pasal 7 disebutkan bahwa operasi ini melibatkan instansi terkait meliputi Tentara Nasional Indonesia, Kepolisian Negara Republik Indonesia, kementerian yang menyelenggarakan urusan pemerintahan di bidang perhubungan, lembaga yang menyelenggarakan urusan pemerintahan di bidang keamanan dan keselamatan laut atau yang disebut dengan nama Badan Keamanan Laut dan kementerian/lembaga pemerintah non kementerian terkait lainnya yang melaksanakan tugas di perairan wilayah Indonesia.

\section{Kesimpulan}

Dari pembahasan yang telah dipaparkan, dapat ditarik kesimpulan yaitu :

1. UNHCR sebagai badan yang memiliki tugas dan tujuan khusus untuk menangani permasalahan pengungsi memiliki peran yang penting dalam memberikan perlindungan dan bantuan bagi para pengungsi dimana mereka berada di luar negaranya sesuai dengan mandat yang diberikan PBB kepada badan tersebut. Peran utama yang dilakukan oleh UNHCR dalam menangani pengungsi adalah sebagai penentu status kepengungsian (determinator) bagi pengungsi yang keluar dari negaranya dan masuk ke negara lain. Selain itu, UNHCR juga memiliki peran sebagai inisiator dan fasilitator (penyedia) perlindungan dan bantuan kemanusiaan bagi para pengungsi suriah di tempat pengungsian. Hal ini dilakukan untuk memastikan bahwa kesejahteraan dan keamanan para pengungsi di tempat pengungsiannya dapat terjamin dan hakhak dasar mereka sebagai manusia dapat terpenuhi dengan baik.

2. UNHCR sebagai badan yang bertugas menangani masalah pengungsi global secara umum dan pengungsi suriah secara khusus juga menyadari hal ini sehingga dalam penanganan pengungsi, UNHCR melakukan Kerjasama dengan organisasiorganisasi internasional dan regional untuk bersama-sama menghadapi masalah pengungsi ini. Organisasiorganisasi tersebut antara lain UNDP, WHO, UNICCEF, UNWFP, UNFPA. Kerjasama ini dilakukan dengan tujuan agar bantuan kemanusiaan dan perlindungan terhadap para pengungsi dapat tersalurkan dengan baik dan hakhak dasar mereka dapat terpenuhi.

\section{Daftar Pustaka}

Setiyono, Joko. 2017. "Kontribusi UNHCR Dalam Penanganan Pengungsi Internasional Di Indonesia." Masalah-Masalah Hukum 46.3 : 275281.

Suyastri, Cifebrima. 2020. "Pendekatan Hubungan Internasional Terhadap Perlindungan Pengungsi: Menjelaskan Inisiatif Kebijakan Pemerintah Indonesia dan UNHCR." Frequency ofInternational Relations (FETRIAN) $2.1: 88-113$.

Rachman, Mohamad Iqbal Jamilurir. .2018. "Kerjasama Indonesia Dengan Lembaga-Lembaga 
Jurnal Sains Riset (JSR)

p-ISSN 2088-0952, e-ISSN 2714-531X

http://journal.unigha.ac.id/index.php/JSR

DOI. $10.47647 /$ jsr.v10i12

TerkaitDalamPenangananPengungsi.

" Jurist-Diction 1.1 : 262-285.

M. Saeri. 2012. "Jurnal Transnasional: Teori Hubungan Internasional, sebuah Pendekatan Pradigmatik". Volume 1, Nomor 2. Hlm 15-17.
P. S., \& Patunru, A. U. T. 2020. Peranan United Nation High Commisioner For Refugees (Unhcr) Terhadap Pengungsi Korban Di Suriah. 